\title{
BMJ Open Investigation assessing the publicly available evidence supporting postmarketing withdrawals, revocations and suspensions of marketing authorisations in the EU since 2012
}

Samantha Lane, ${ }^{1}$ Elizabeth Lynn, ${ }^{1,2}$ Saad Shakir ${ }^{1,2}$

To cite: Lane S, Lynn E, Shakir S. Investigation assessing the publicly available evidence supporting postmarketing withdrawals, revocations and suspensions of marketing authorisations in the EU since 2012. BMJ Open 2018;8:e019759. doi:10.1136/ bmjopen-2017-019759

- Prepublication history and additional material for this paper are available online. To view these files, please visit the journal (http://dx.doi.org/10. 1136/bmjopen-2017-019759)

Received 22 September 2017 Revised 15 December 2017 Accepted 19 December 2017

Check for updates

${ }^{1}$ Drug Safety Research Unit, Southampton, Hampshire, UK ${ }^{2}$ School of Pharmacy and Biomedical Sciences, University of Portsmouth, Portsmouth, UK

Correspondence to

Miss Samantha Lane; samantha.lane@dsru.org

\section{ABSTRACT}

Objectives To assess the sources of publicly available evidence supporting withdrawal, revocation or suspension of marketing authorisations ('regulatory actions') due to safety reasons in the EU since 2012 and to investigate the time taken since initial marketing authorisation to reach these regulatory decisions.

Setting This investigation examined the sources of evidence supporting 18 identified prescription medicinal products which underwent regulatory action due to safety reasons within the EU in the period 1 July 2012 to 31 December 2016.

Results Eighteen single or combined active substances ('medicinal products') withdrawn, revoked or suspended within the EU for safety reasons between 2012 and 2016 met the inclusion criteria. Case reports were most commonly cited, supporting $94.4 \%$ of regulatory actions $(n=17)$, followed by randomised controlled trial, metaanalyses, animal and in vitro, ex vivo or in silico study designs, each cited in $72.2 \%$ of regulatory actions $(n=13)$. Epidemiological study designs were least commonly cited $(n=8,44.4 \%)$. Multiple sources of evidence contributed to $94.4 \%$ of regulatory decisions $(n=17)$. Death was the most common adverse drug reaction leading to regulatory action $(n=5 ; 27.8 \%)$, with four of these related to medication error or overdose. Median (IQR) time taken to reach a decision from the start of regulatory review was found to be 204.5 days $(143,535$ days) and decreased across the study period. Duration of marketing prior to regulatory action, from the medicinal product's authorisation date, increased across the period 2012-2016.

Conclusions The sources of evidence supporting pharmacovigilance regulatory activities appear to have changed since implementation of Directive 2010/84/EU and Regulation (EU) No. 1235/2010. This, together with a small improvement in regulatory efficiency, suggests progress towards more rapid regulatory decisions based on more robust evidence. Future research should continue to monitor sources of evidence supporting regulatory decisions and the time taken to reach these decisions over time.

\section{INTRODUCTION}

Due to the limitations related to external validity and incomplete safety data from
Strengths and limitations of this study

- This is the first study to examine the sources of evidence supporting withdrawal, revocation or suspension of Marketing Authorisations since the implementation of Directive 2010/84/EU and Regulation (EU) No. 1235/2010.

- This study identifies trends in the time taken to reach a regulatory decision.

- Data are based on a small number of marketing authorisation withdrawals, revocations or suspensions.

- There were limited data publicly available on reasons for regulatory decision and supporting evidence, particularly for regulatory actions occurring in single Member States.

- Authorisation dates used to calculate time on the market prior to regulatory action may not have been accurate for all active substances.

premarketing trials, much of the evidence regarding the safety of a medicinal product is established in the postmarketing phase. ${ }^{12}$ Adverse drug reactions (ADRs) can lead to increased morbidity, permanent, long-term or life-changing complications requiring hospitalisation or medical intervention and death. $^{3}{ }^{4}$ An estimated 5\% of all hospital admissions and 197000 deaths are attributable to ADRs each year in the EU; ADRs are the fifth most common cause of death in Europe and amount to an annual societal cost of approximately $€ 79$ billion. ${ }^{5-7}$ In this context, an initiative to update existing pharmacovigilance legislation was commenced; Directive 2010/84/EU and Regulation (EU) No. 1235/2010 were implemented in June 2012 and further amended in October 2012. ${ }^{6}$ Two declared aims of these legislations were 'the collection of better data on medicines and their safety' and 'rapid and robust assessment of issues related to the safety of 
medicines. ${ }^{6}$ If there is sufficient evidence of an unfavourable benefit-risk balance or emerging safety issue, such assessments can result in major pharmacovigilance action such as withdrawal, revocation or suspension of a medicinal product's marketing authorisation (henceforth 'regulatory action'). ${ }^{2689}$

The sources of evidence supporting regulatory actions have been previously studied in different regions. ${ }^{210-15}$ Arnaiz et al researched products withdrawn from Spanish market from 1990 to 1999, Clarke et al explored UK and USA withdrawals between 1999 and 2001, while Olivier and Montastruc investigated withdrawals in France from 1998 to $2004 .{ }^{2}{ }^{12} 13$ Paludetto et al examined active ingredients withdrawn from the French market in the period 2005-2011 and McNaughton et al investigated European product withdrawals between 2002 and 2011. ${ }^{11}{ }^{15}$ More recently Alves $e t$ al studied safety alerts in USA, Canada, the EU and Australia between 2010 and 2012, while Onakpoya $e t$ al researched product withdrawals from markets worldwide (including EU market) in the period 19532013. ${ }^{10}{ }^{14}$ All of these studies concluded that spontaneous case reports were the most frequently used evidence to support pharmacovigilance activities, with a range of $56 \%-95 \%$ of identified regulatory actions being supported by case reports or case series. Four studies reported that $4.5 \%-36 \%$ of regulatory actions were a consequence of case reports alone. ${ }^{2101213}$ Other cited sources of evidence were clinical trials, observational or epidemiological studies, animal studies, systematic reviews and meta-analyses. Three of the most recent studies reported a higher number of regulatory actions supported by clinical trials compared with the earlier studies, suggesting a recent shift towards more robust evidence supporting regulatory actions. ${ }^{101115}$ Conversely Mendes et al reported types of evidence supporting withdrawals from EU market from 2001 to 2015 and used results of cited premarketing and postmarketing studies to calculate number needed to treat to be harmed, to assess the usefulness of this metric in evaluation of benefit-risk ratios. ${ }^{16}$

Trials conducted in the premarketing phase often lack external validity due to many factors including limited generalisability to a medicinal product's clinical use, small sample sizes and limited periods of observation. ${ }^{17}$ Therefore, postmarketing reporting of ADRs during real-world clinical use of a medicinal product is an important factor in identifying new, rare and serious ADRs with potential to affect the benefit-risk balance of the product. ${ }^{1018}$ These reporting systems can also provide further information for ADRs already identified but not adequately understood. However, it is widely accepted that under-reporting of ADRs occurs in both spontaneous reporting systems and the published literature, for reasons such as publication bias, which impedes signal detection by pharmacovigilance. ${ }^{19}{ }^{20}$ Furthermore, while spontaneous ADR reports are an effective method of identifying safety signals, spontaneous reporting systems have limitations such as lack of information on the total number of exposed individuals (denominators) and under-reporting of ADRs, with suggestions that less than $10 \%$ of ADRs are reported. ${ }^{10} 21-24$ Therefore it has been suggested that high-quality evidence is necessary to improve the quality and efficacy of public health interventions. ${ }^{13} 25$ All previous studies of evidence supporting marketing authorisation withdrawals from EU markets identified spontaneous ADR reports or published case reports as the most commonly cited evidence supporting regulatory action due to safety issues; however, with the EU legislation change in 2012, there was the hope for more robust evidence leading to more rapid regulatory actions. It was expected that the results of this study would provide evidence of a recent shift from reliance on case reports towards the use of data from more robust study designs, thus avoiding the limitations associated with spontaneous reporting of ADRs.

The effectiveness of pharmacovigilance and regulatory processes is not currently monitored using a systematic approach. Therefore, this study is important because our investigation of recent trends in the timelines of regulatory actions and the changes to supporting evidence may help to inform more effective evaluation of drug safety in future. Recognition of a change in evidence used during reviews may allow regulators to base future evaluations on reliable evidence, thus preventing access to harmful medicinal products more rapidly in populations most at risk. The results of this study may also provide insight into current regulatory methods for manufacturers, healthcare professionals and patients, consequently enhancing their understanding of these processes.

With the exception of the study by Onakpoya $e t$ al which concluded in 2013, all previous studies investigating sources of supporting evidence were completed prior to the adoption of Directive 2010/84/EU and Regulation (EU) No. 1235/2010 in 2012; thus, there is no study that specifically investigates changes to the sources of evidence supporting regulatory action in the EU market since the implementation of this legislation. ${ }^{14}$ The objectives of this study were to assess the sources of evidence supporting postmarketing withdrawal, revocation suspension of Marketing Authorisations since the adoption of Directive 2010/84/EU and Regulation (EU) No. 1235/2010 and to investigate the time taken to reach the regulatory decision.

\section{METHODS}

Individual or combined active substances ('medicinal products') available on prescription whose marketing authorisations underwent withdrawal, revocation or suspension in all or individual EU Member States plus Norway, Liechtenstein and Iceland for postmarketing safety reasons between 1 July 2012 and 31 December 2016 were identified. Detailed searches of the European Medicines Agency (EMA) website and List of Withdrawn Products, WHO publications (WHO Pharmaceuticals Newsletter and WHO Drug Information) and national regulatory websites and newsletters of all EU 
Table 1 Study designs used to support withdrawal, revocation or suspension of medicinal products (adapted from Clarke et $a l^{2}$ )

\begin{tabular}{|c|c|}
\hline Type of study & Description \\
\hline Case report & $\begin{array}{l}\text { Individual case safety report or case series identified in the published medical or scientific literature } \\
\text { or adverse drug reactions reported spontaneously by healthcare professionals and/or patients to } \\
\text { national pharmacovigilance centres or the Marketing Authorisation Holder. }\end{array}$ \\
\hline Animal & In vitro or in vivo studies using whole animals or animal tissue. \\
\hline Observational & $\begin{array}{l}\text { Non-interventional study in which the strength of association between exposure and outcome is } \\
\text { observed. }{ }^{41} \text { Types of observational study include case-control, cohort and cross-sectional. }\end{array}$ \\
\hline Cohort & $\begin{array}{l}\text { A cohort of individuals who are known to have been exposed to the causative agent are observed } \\
\text { prospectively for development of the outcome of interest. A second group of controls (ie, have not } \\
\text { received the drug of interest) may also be observed. }\end{array}$ \\
\hline Cross-sectional & $\begin{array}{l}\text { Observation of a defined population at a given point in time, where exposure and outcome are } \\
\text { defined simultaneously. }\end{array}$ \\
\hline $\begin{array}{l}\text { Meta-analysis or } \\
\text { Systematic review }\end{array}$ & $\begin{array}{l}\text { A quantitative, formal, epidemiological study design in which all previous studies on a topic } \\
\text { that meet set eligibility criteria are identified and systematically analysed to give more precise } \\
\text { information regarding an outcome in comparison with any one study contributing to the pooled } \\
\text { data. }^{42}\end{array}$ \\
\hline In vitro, ex vivo or in silico & $\begin{array}{l}\text { Studies taking place in vitro or ex vivo using assays, cell lines or human tissue or in silico (ie, } \\
\text { computerised). }\end{array}$ \\
\hline Non-placebo controlled & Uncontrolled studies or those with an active comparator used as control. \\
\hline $\begin{array}{l}\text { Non-randomised, open- } \\
\text { label/non-blinded or non- } \\
\text { comparative }\end{array}$ & Studies that were not randomised, blinded or those without a comparator group. \\
\hline Other & Retrospective, within-subject or crossover studies. \\
\hline
\end{tabular}

Member States plus Norway, Lichtenstein and Iceland were conducted to identify eligible medicinal products. Details of the search strategy are available as an online supplementary appendix. Despite their extensive use in regulatory documentation, no explicit definition of each regulatory action was identified. 'Withdrawal' and 'revocation' appear to be interchangeable terms within regulatory documentation; we perceived these terms to mean a complete removal of the medicinal product from the market, with no further availability to patients. 'Suspension' was defined as access to the medicinal product by all patients was prohibited until a change to the medicinal product or its labelling, and therefore an improvement in its safety, was made. Further information regarding regulatory procedures is available on the EMA website. ${ }^{26-29} \mathrm{~A}$ 'safety reason' was defined as an unfavourable benefit-risk balance or evidence of a causal relationship between the medicinal product and the cited ADR, including those resulting from misuse and maladministration as per the definition in good pharmacovigilance practices (GVP). ${ }^{29}$ The GVP definition of ADR was used to establish the ADRs contributing to regulatory action. ${ }^{29}$ As misuse, medication error and accidental overdose are possible risk factors for potentially serious ADRs, where applicable these terms with their resultant $\mathrm{ADR}(\mathrm{s})$ have been considered in the analyses.

All medicinal products available on prescription that were withdrawn, revoked or suspended for safety reasons across all EU Member States in addition to those that underwent regulatory action in one or more individual Member States during the time period 1 July 2012 to 31 December 2016 were considered for inclusion. Generics and single formulations, indications or strengths that were withdrawn, revoked or suspended during the same period were included. The GVP definition for 'medicinal product' was used. ${ }^{29}$ A medicinal product was included in the analysis only when the final regulatory decision was made during the 1 July 2012 to 31 December 2016 study period; however, procedural start dates may have been prior to this period. Vaccines and products or batches temporarily discontinued or recalled were not included in this study.

The EMA and individual national regulatory authorities were contacted via contact forms on their public webpages for further information regarding five medicinal products for which there was little freely available information regarding reasons for their withdrawal, revocation or suspension. A request was submitted for details 


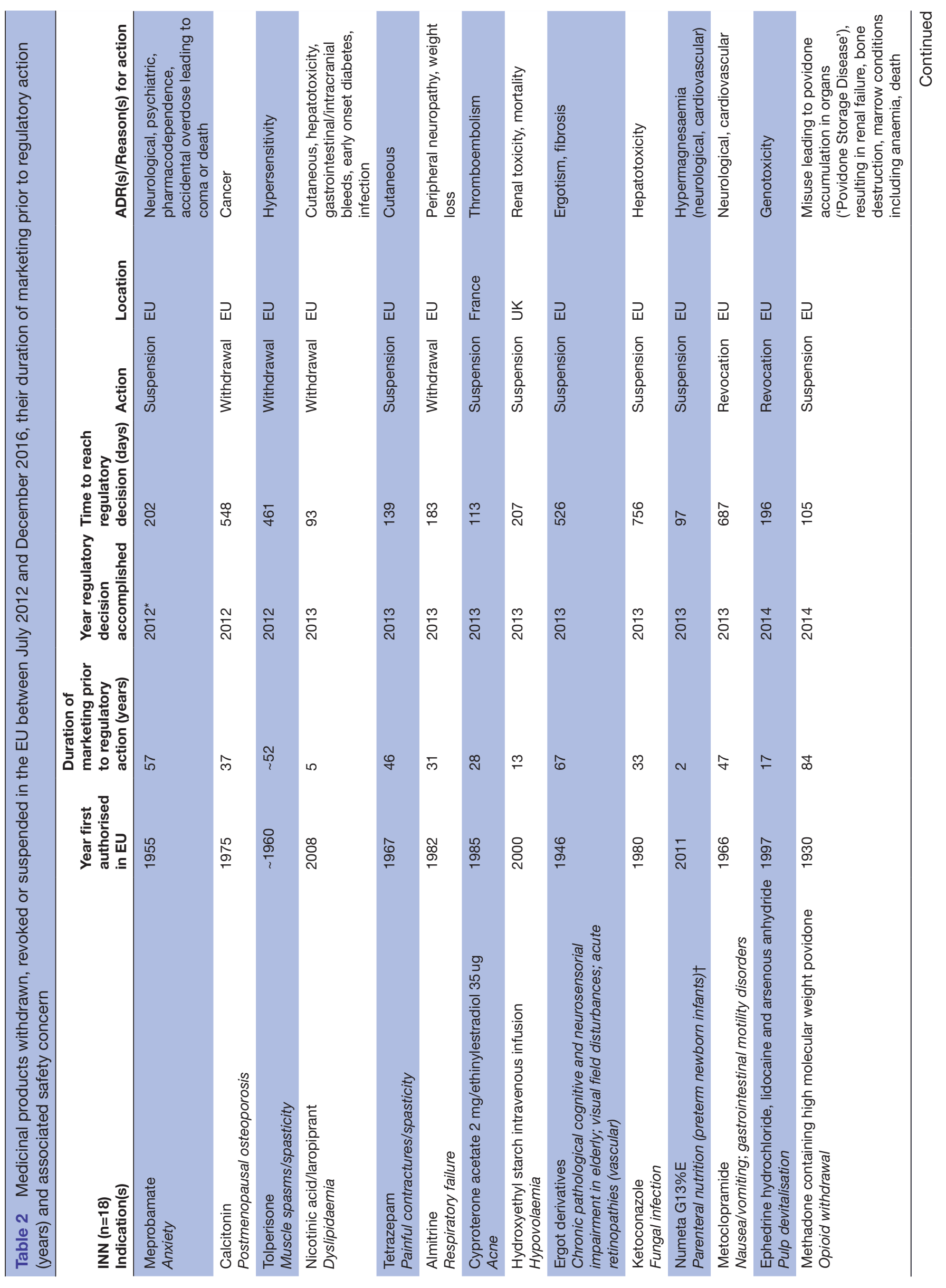

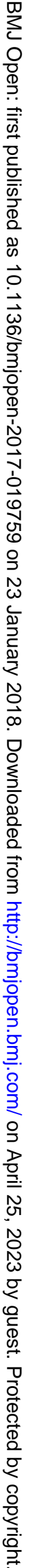



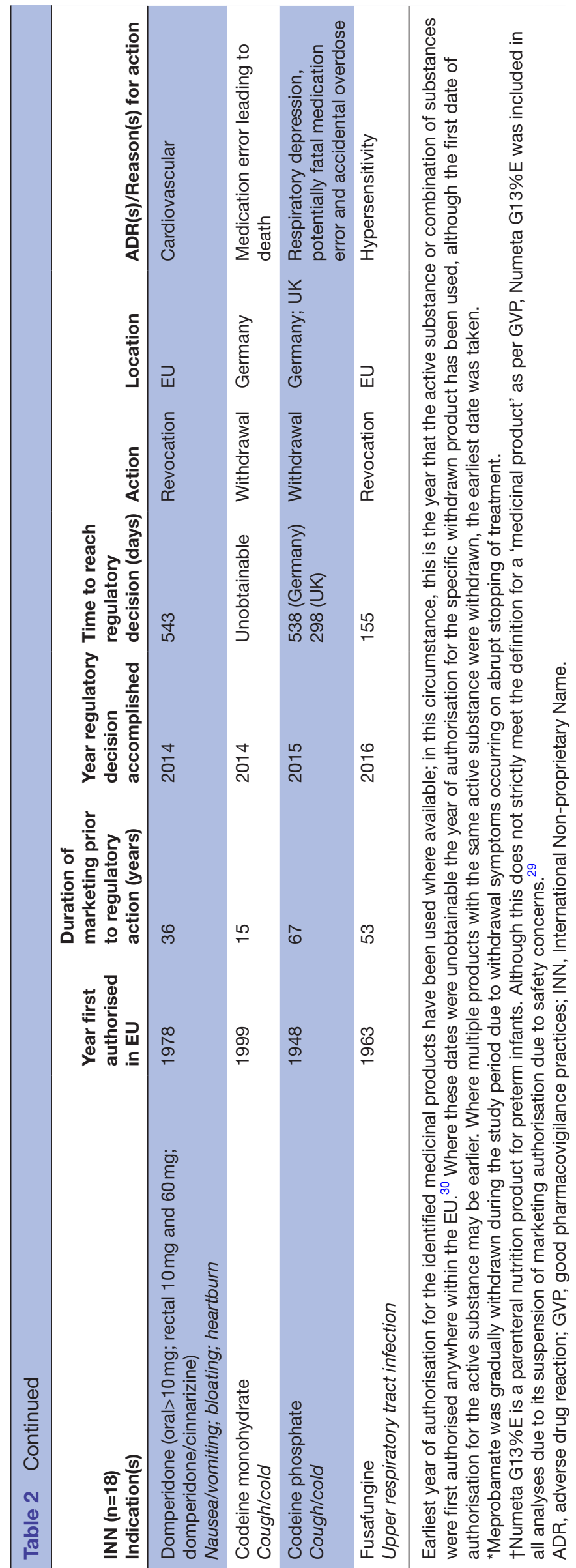

of evidence used to reach the regulatory decision. The response deadline was set for 3 July 2017 , after which time the respective medicinal product would be automatically excluded.

For each identified and eligible medicinal product, the sources of publicly available evidence contributing to the benefit-risk evaluation, thus supporting the withdrawal, revocation or suspension was assessed. Sources of cited evidence included EMA publications (Questions and Answers, Press Releases, Assessment Reports and Scientific Conclusions), Marketing Authorisation Holders' (MAHs') webpages, national regulatory authorities' webpages and publications (eg, Dear Healthcare Provider letters), pharmaceutical newsletters and the scientific literature. A search was carried out in PubMed using the International Non-proprietary Name (INN) in combination with the following:

1. 'Adverse effect,' adverse reaction,' 'adverse event,' 'side effect,' or 'toxicity;'

2. The specific safety concern (ADR) given as reason for withdrawal, revocation or suspension by the EMA.

Evidence sourced from the published literature and studies contributing to the benefit-risk evaluation and therefore overall regulatory decision to withdraw, revoke or suspend a medicinal product, as cited within regulatory documentation, were categorised according to study design (table 1). Only studies reporting significance were included. Literature published up to and including 12 months postregulatory action were included, which accounted for a delay between the end of a study and its publication.

Time to reach a regulatory decision was calculated for each medicinal product, using both the first year of authorisation within the EU and the procedural start date; the latter is defined as the date that the regulatory review process commenced, given in regulatory documentation and thus provided an indicator of regulatory efficiency.

\section{Data analysis}

Frequencies and, where appropriate, proportions were calculated for medicinal products, location of regulatory action, year of final regulatory decision, ADR given as reason for regulatory action and study designs used in regulatory decision-making.

Medians with IQR were calculated for the duration of marketing and the time to reach a regulatory decision from procedural start date. This measure was selected due to the small number of medicinal products included in analysis and because the median is less influenced by extreme values compared with the mean.

An analysis of variance statistical test was used to determine any statistical difference in the time to reach a regulatory decision, when grouped by year.

SL was responsible for data acquisition and analyses. All researchers were involved with interpretation of the results. 









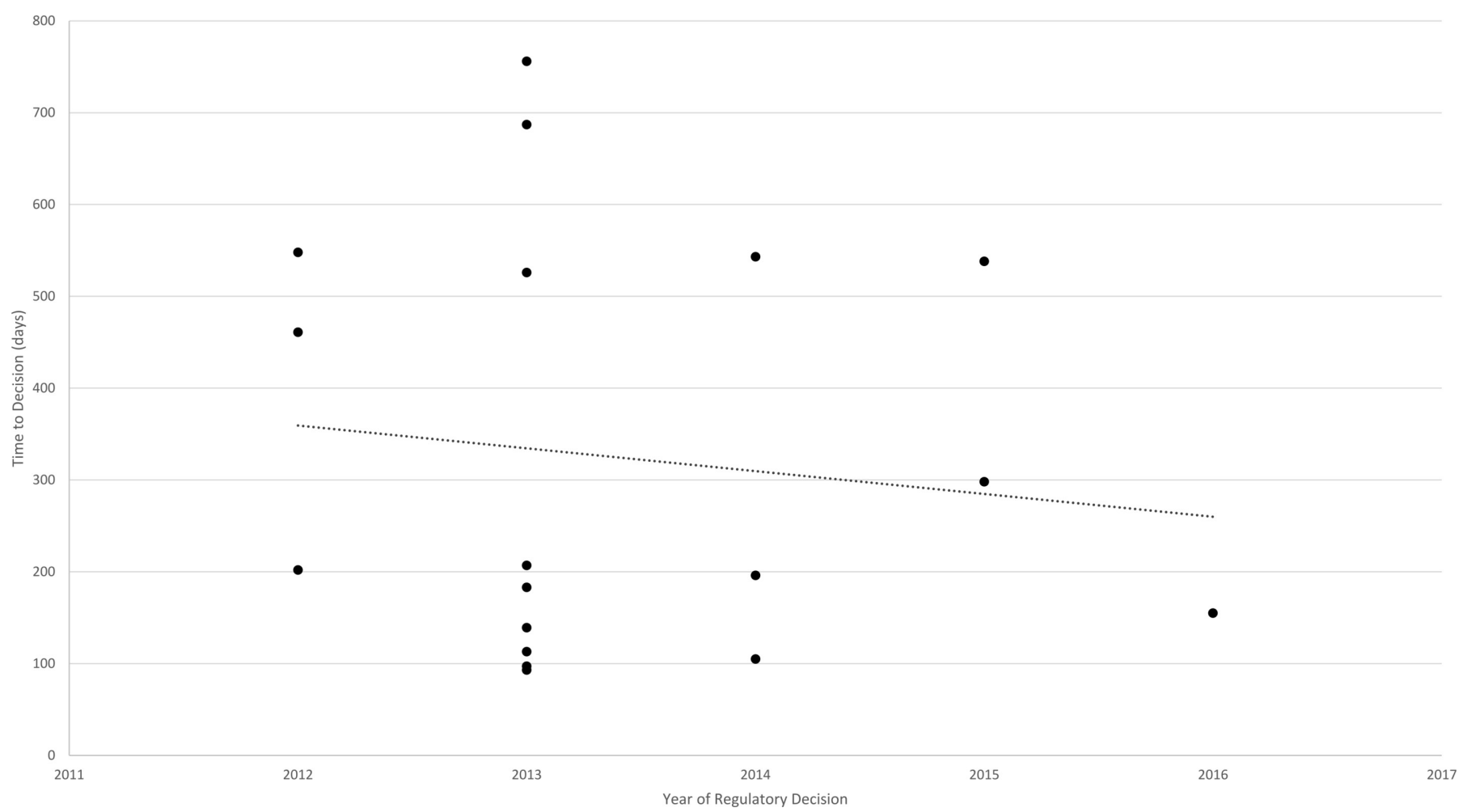

Figure 1 Time to reach a regulatory decision (days) from procedural start date, by year of regulatory action.

\section{RESULTS}

Eighteen medicinal products withdrawn, revoked or suspended within the EU between 1 July 2012 and 31 December 2016 met the inclusion criteria; these are displayed in table 2. Three quarters $(\mathrm{n}=14,77.8 \%)$ of the 18 medicinal products identified underwent regulatory action in all EU Member States in which the medicinal product was previously authorised. Two additional medicinal products underwent regulatory action solely in Germany, two in UK and one was suspended in France. Of all regulatory actions that took place between July 2012 and December 2016, $88.9 \%(n=16)$ occurred before 2015. Half of all regulatory actions occurred during 2013 ( $\mathrm{n}=9,50.0 \%)$. It should be noted that only the second half of 2012 was included in the study period, therefore a perhaps smaller than expected number of actions occurred during 2012. Overall suspension of marketing authorisation was the most common regulatory action during the study period $(\mathrm{n}=8,44.4 \%)$, followed by withdrawal $(n=6,33.3 \%)$. The remaining four actions were described as revocation of marketing authorisation $(22.2 \%)$. An additional five withdrawals, revocations or suspensions in individual Member States were identified for the 2012-2016 period; however, information regarding these actions was unavailable or unobtainable in the public domain. The appropriate regulatory authorities were contacted via their public webpage for additional information. A response was received from the Portuguese authority, Infarmed, regarding a Diclofenac Sodium product (Painex), stating that this was suspended following the MAH's non-submission of relevant variations to product information following a PRAC review in 2013, therefore not due to a safety reason (personal communication from Infarmed, 2017). The four remaining medicinal products underwent regulatory action in either France or Germany; however, no further information was provided by the respective regulatory agencies before the response deadline. All five regulatory actions were therefore excluded from the analyses, as it was not possible to identify whether the inclusion criteria of withdrawal, revocation or suspension of marketing authorisation due to a safety reason could be met.

\section{Sources of supporting evidence}

Table 3 describes the study designs of evidence supporting the regulatory action for each of the 18 identified medicinal products. The most commonly cited source of evidence was spontaneous ADR report or published case report, contributing to 17 (94.4\%) of the 18 identified withdrawals, suspensions and revocations. The withdrawal of one medicinal product (5.6\%) was based solely on spontaneous case reports, whereas just one of the regulatory actions (nicotinic acid/laropiprant; $\mathrm{n}=1,5.6 \%$ ) did not possess spontaneous or published case reports cited as supporting evidence. The remaining 16 regulatory actions were evidenced by spontaneous or published case reports plus at least two additional sources of evidence. Each of these regulatory actions had case reports cited as supporting evidence in EMA or the specific regulatory body's documentation (88.9\% of total actions; $94.1 \%$ of all actions based on spontaneous or published case 




Figure 2 Duration of marketing (years) from year first authorised in the EU to regulatory decision date, grouped by year of regulatory decision accomplishment.

reports). The study designs least frequently cited both by regulatory agencies and in the scientific literature were epidemiological in nature; cross-sectional studies contributed to 2 of the 18 regulatory actions $(11.1 \%)$ and were cited in the regulatory reports only, whereas other (epidemiological) studies (ie, ecological studies and those that do not fit within the epidemiological classifications provided in table 1) were the least frequently cited study design used as supporting evidence by regulators. Indeed, epidemiological study designs altogether were not commonly found to be supporting evidence in the identified regulatory actions, contributing to just eight $(44.4 \%)$ regulatory decisions. Interestingly just 1 of the 13 regulatory actions with randomised controlled trials (RCTs) sourced from the published literature $5.6 \%$ of total regulatory actions) did not have this study design cited by the regulator.

\section{Adverse reactions given as reason for regulatory action}

Fatalities were reported in 5 of the 18 regulatory actions (27.8\%; table 2), suggesting death was the most common ADR contributing to regulatory decisions in these medicinal products. Four of these actions were related to medication error, accidental overdose or misuse of the substance. Cardiovascular and haematological events and neurological events were the second most commonly provided reasons for regulatory action, each contributing to 4 of the 18 actions $(22.2 \%)$. It should be noted that the identified medicinal products containing codeine phosphate were withdrawn following the restriction of use of codeine in the treatment of cough and cold in children. $^{31}$

\section{Time to reach a regulatory decision}

There was a modest, non-significant decrease $(\mathrm{P}=0.8711)$ in time between the procedural start date and final regulatory decision (in days) across the study period (figure 1). The year 2013 saw the medicinal product with the longest time to reach a regulatory decision (ketoconazole; $\mathrm{n}=756$ days; procedural start date 1 July 2011), as well as the shortest (nicotinic acid/laropiprant; $n=93$ days; procedural start date 20 December 2012). Across the whole time period studied, the median (IQR) time to reach a regulatory decision was 204.5 days (143, 535 days). A procedural start date for codeine monohydrate was not available; therefore, time to reach a regulatory decision for this medicinal product was excluded from this analysis. Two codeine phosphate products underwent regulatory action in individual Member States in 2015, both with a different procedural start date; both have been included in this analysis and thus two measures can be seen for the year 2015 in figure 1. For the purpose of this analysis, meprobamate was considered withdrawn in 2012.

\section{Duration of marketing prior to regulatory action}

Duration of marketing prior to withdrawal, revocation or suspension between 2012 and 2016 ranged from 2 years 
Table 4 Description of studies and marketing durations identified in published literature

\begin{tabular}{|c|c|c|c|}
\hline $\begin{array}{l}\text { Study authors, } \\
\text { year of publication }\end{array}$ & $\begin{array}{l}\text { Sample size (number } \\
\text { of products) }\end{array}$ & Setting & $\begin{array}{l}\text { Median duration of } \\
\text { marketing }\end{array}$ \\
\hline $\begin{array}{l}\text { Onakpoya et al, } \\
2016\end{array}$ & 462 & $\begin{array}{l}\text { Postmarketing withdrawals from worldwide } \\
\text { markets, 1953-2013 }\end{array}$ & 18 years (IQR: 6-34 years) \\
\hline $\begin{array}{l}\text { McNaughton et al, } \\
2014\end{array}$ & 19 & $\begin{array}{l}\text { Withdrawals from EU market for } \\
\text { pharmacovigilance reasons, 2002-2011 }\end{array}$ & 23 years (IQR: $4-46$ years) \\
\hline $\begin{array}{l}\text { Paludetto et al, } \\
2012\end{array}$ & 22 & $\begin{array}{l}\text { Withdrawals in France for safety reasons, } \\
\text { 2005-2011 }\end{array}$ & $\begin{array}{l}22 \text { years (range: } \\
7 \text { months }-51 \text { years) }\end{array}$ \\
\hline $\begin{array}{l}\text { Clarke et al, }{ }^{2} \text { reported in } \\
\text { McNaughton et al, }{ }^{11} \\
2006\end{array}$ & $\operatorname{six}$ of $11^{*}$ & Withdrawal from UK market, 1999-2001 & 5 years (IQR: $4-10.5$ years) \\
\hline $\begin{array}{l}\text { Olivier and Montastruc, } \\
2006\end{array}$ & 21 & $\begin{array}{l}\text { Withdrawal from French market for safety } \\
\text { reasons, 1998-2004 }\end{array}$ & 33.2 years \\
\hline
\end{tabular}

*Duration of marketing prior to withdrawal was calculated for 6 of the 11 products identified in the study by Clarke et al. ${ }^{2}$ These were calculated and presented in the paper by McNaughton et al. ${ }^{11}$

†22 of the 583 new active substances identified by Jeffreys et al ${ }^{36}$ were withdrawn from market due to safety reasons. Therefore, these products only were included in this analysis.

to 84 years. Median (IQR) time on the market was 36.5 years $(15,57$ years $)$ and increased across the study period (figure 2, table 2).

\section{DISCUSSION}

The types of evidence used to justify 18 withdrawals, revocations or suspensions of marketing authorisations within the EU between 1 July 2012 and 31 December 2016 were assessed. The most commonly cited evidence source contributing to these regulatory decisions was spontaneously reported or published case reports $(n=17$, $94.4 \%)$. RCT, meta-analyses, animal and in vitro, in vivo or in silico study designs were each cited in 13 of the 18 $(72.2 \%)$ regulatory actions. Interestingly, epidemiological study designs were the least commonly cited evidence source in supporting these regulatory decisions $(n=8$; $44.4 \%$ ). Most commonly death was given as a reason for commencing regulatory review $(n=5,27.8 \%)$. The median time to reach a regulatory decision from procedural start date was 204.5 days ( $\mathrm{IQR}=143-535$ days), whereas the median duration of marketing prior to regulatory action was 36.5 years $(\mathrm{IQR}=15-57$ years $)$.

\section{Comparison with pre-2012 data}

Of the 18 regulatory actions included in this study, $88.9 \%(n=16)$ occurred in the first half of our study period. This may indicate that fewer regulatory actions are occurring over time since the introduction of Directive 2010/84/EU and Regulation (EU) No. 1235/2010. Overall a smaller number of marketing authorisation withdrawals were observed postimplementation of the pharmacovigilance legislation updates (6 of the total 18 actions included in this study) in comparison with studies examining market withdrawals pre-2012. This may imply that medicinal products are less likely to be withdrawn since 2012. A possible reason for these observations is that requirements of the updated legislations ensure that only well-tested, safer medicinal products are approved for use, with more stringent safety surveillance in their early postmarketing phase. Based on existing literature, it is not possible to determine a trend in revocations or suspensions spanning preimplementation and postimplementation of the updated pharmacovigilance legislation. One study published in 2013 examined safety alerts; of 59 alerts identified, just one medicinal product had been suspended. Conversely in our study, it was found that eight suspensions had occurred since 1 July 2012. Therefore, it may be that a higher number of medicinal products are now being suspended in comparison with pre-2012, perhaps as an alternative to marketing authorisation withdrawal. It should be noted, however, that our sample of medicinal products is too small and too short a period of time has passed since the implementation of legislative changes to draw robust conclusions from these data.

\section{Sources of supporting evidence}

The results of this study suggest that both spontaneous and published ADR reports remain the most common source of evidence contributing to regulatory action in the EU, with 17 of 18 identified withdrawals, revocations or suspensions (94.4\%) justified by this type of evidence. This is in line with previous studies which all described spontaneous reports and published case reports as the most commonly cited evidence supporting regulatory 
action. $^{2}{ }^{10-15}$ In our study, one withdrawal (5.6\%) was supported solely by spontaneous reports; this is considerably lower than figures reported previously. Olivier and Montastruc suggested that $57 \%$ of withdrawals from French market in the period 1998-2004 were solely based on spontaneous reports and case series, whereas more recently Alves et al reported that $20 \%$ of the identified products withdrawn in the EU, USA, Canada and Australia between 2010 and 2012 had been justified using postmarketing spontaneous reports alone. ${ }^{10}$ Previous research examining the evidence for withdrawals between 1998 and 2001 reported rates of $4.8 \%-18 \%$ of withdrawals supported by RCTs, whereas more recently, in the period 2005-2012, reported rates of safety alerts identified by RCTs and regulatory actions supported by RCTs have increased to between $41 \%$ and $63 \% .^{2}{ }^{10-12} 15$ The findings of our study are consistent with previous literature suggesting a recent increase in RCTs used as supporting evidence; it was found here that RCTs were used in $72.2 \%$ $(n=13)$ of identified regulatory actions. However, there are limitations surrounding the use of RCTs in assessing the safety of medicinal products; in this context the lack of epidemiological studies cited in the 18 identified regulatory actions is interesting, as both interventional and observational designs are considered necessary in the study of drug effects when their limitations are taken into account. $^{32}$

Paludetto et al reported that $68 \%$ of the identified products withdrawn in France between 2005 and 2011 had been supported by multiple sources of evidence whereas in our study $94.4 \%$ of identified regulatory actions were justified by multiple sources of supporting evidence, suggesting a possible recent shift towards the use of more robust evidence in regulatory decisions. ${ }^{15}$ However, it is important to note that the sources of evidence used by National Competent Authorities greatly varied when supporting regulatory actions in individual Member States and in particular when compared with evidence sources used by the EMA.

\section{Adverse reactions given as reason for regulatory action}

Most commonly death was the ADR given as reason for regulatory action in the 18 identified actions $(n=5$, $27.8 \%$ ); reports of deaths as a reason for regulatory action in previous studies are variable, ranging from $2.4 \%$ to $27.3 \% .^{2} 101113-15$ One study reported no regulatory actions associated with death. ${ }^{12}$ The results of our study showed a higher number of medicinal products with death cited as a reason for regulatory action in comparison with previously published results. Previously, hepatotoxicity was most commonly reported to lead to regulatory action, while this ADR contributed to just two regulatory actions in this study. ${ }^{11-15} 3334$ Neurological and cardiovascular events were also commonly implicated in the literature, supporting our findings that cardiovascular and haematological ADRs and neurological ADRs each contributed to four regulatory decisions $(22.2 \%) .^{211-1315}$
Of the five regulatory actions relating to death in this study, four actions $(80 \%$; $22.2 \%$ overall) were also associated with reports of misuse, medication error or accidental overdose. Previously, there have been variations in the rates of reporting of misuse, medication error and overdose contributing to regulatory actions. For instance, Onakpoya et al suggested that $11 \%$ of identified products withdrawn from market in Europe, the Americas, Asia, Australasia and Africa between 1953 and 2013 were related to drug abuse or dependence, whereas in the European setting, Paludetto et al, Olivier and Montastruc and McNaughton et al each cited two withdrawals with abuse or misuse as a contributing factor. ${ }^{11121415}$ Overdose was reported as contributing to regulatory decision by Paludetto $e t$ al and McNaughton $e t$ al in four cases and one case, respectively; however, no actions were reportedly associated with overdose in the 2006 study by Olivier and Montastruc. ${ }^{11} 1215$ This suggests that overdose has recently become more widely recognised as a safety issue that could lead to regulatory action. In some cases, medicinal products have undergone regulatory action when risk minimisation measures have failed to reduce the detrimental public health impact. Furthermore, when Directive 2010/84/EU and Regulation (EU) No. 1235/2010 were implemented in 2012, misuse, medication error and overdose were added to the definition of an ADR and could be considered a risk factor for ADRs; therefore, it is likely that these will more frequently contribute to regulatory decisions in the future compared with the period prior to the legislation being in effect. ${ }^{35}$

\section{Time to reach a regulatory decision}

The median (IQR) time taken to reach a regulatory decision from the procedural start date to decision date was 204.5 days (143, 535 days). Data surrounding the length of EMA review periods prior to the adoption of the updated pharmacovigilance legislation in 2012 have not been previously published. Between 2012 and 2016, there was a small decrease in the number of days taken to reach a regulatory decision. However, statistical analysis provided no evidence to support this $(\mathrm{P}=0.8711)$; therefore, it may be that there has not been any improvement in the duration of regulatory reviews since 2012 and the decreasing trend occurred by chance. However, as these data are based on a small number of regulatory actions, evidence of a reduction in time to reach a regulatory decision may be found in a larger number of regulatory actions over a longer period of time. As a stated aim of the 2012 legislative changes was more rapid decisions to protect patients from harmful substances sooner, analysis of trends in the lengths of regulatory review periods is a necessary area of future research.

\section{Duration of marketing prior to regulatory action}

There is variation in duration of marketing prior to regulatory action reported in the published literature, with median duration of marketing ranging from 4 years to 33.2 years (table 4 ). Conversely, Lasser et al described that 
most withdrawals identified in their study of the US market between 1975 and 2000 occurred within 2 years postmarketing. ${ }^{34}$ The median (IQR) duration of marketing in our study was 36 years $(15,57$ years), which contradicts those previously described. The well-established nature of many medicinal products identified in our study could explain a longer average time on the market.

Onakpoya et al suggested that the more recent the launch year, the shorter the time on the market prior to regulatory action and Fung et al reported a similar trend; average duration of marketing prior to withdrawal from markets worldwide was found to decrease for products with more recent launch years in their study period 19601999, with an overall median duration of marketing of 5.4 years. ${ }^{1433}$ Due to the relatively long average time on market for the medicinal products included in our study, it can be seen that there can be a long period of time during which many patients may be put at risk by exposure to these substances. In the future, it is necessary to continue with pharmacovigilance efforts early in the postmarketing phase to ensure early recognition of the risks associated with new medicinal products.

Excluding data on products identified by Clarke $e t a l^{2}$ due to calculation of the duration of marketing by other authors and thus a lack of evaluation of trends, four of the studies identified in the published literature established a decreasing trend in average duration of marketing prior to regulatory action over time. ${ }^{14} 153336$ Although the remaining studies did not report trends within their data, each demonstrated a longer duration of marketing prior to regulatory action in comparison with earlier research. ${ }^{11} 12$ The duration of marketing for medicinal products that underwent regulatory action between 2012 and 2016 increased over time, demonstrated by the trend line in figure 2. In comparison with established medicinal products, new medicinal products undergo more frequent safety surveillance in the form of Periodic Safety Update Reports (PSURs) and other postauthorisation safety studies. ${ }^{37}$ It should be noted that data presented in these PSURs have been cited in selected documentation relating to regulatory action. Additionally, the Adaptive Pathways scheme allows early and progressive patient access to certain new medicinal products. ${ }^{38}$ This potentially extends the postmarketing duration of the medicinal products approved via this approach; in future, it may be interesting to perform analyses on duration of marketing for products authorised via the Adaptive Pathways scheme and assess how these actions impacted the duration of marketing prior to regulatory action for all medicinal products that underwent regulatory action during the same timeframe. However, it may take time for ADRs to be recognised as serious enough to justify regulatory action, providing a potential reason for the longer durations of marketing prior to regulatory action observed for the medicinal products identified in this study.

Paludetto et al suggested that the use of multiple evidence sources in regulatory decisions may decrease the duration of marketing before withdrawal. ${ }^{15}$ There may be some evidence in our findings to support this; the number of evidence sources supporting regulatory decisions were most numerous in 2013, when the three medicinal products with the shortest duration of marketing underwent regulatory action. However, there was wide variation in duration of marketing prior to regulatory action among the other medicinal products withdrawn, revoked or suspended in 2013. Furthermore, the average duration of marketing for medicinal substances with multiple sources of evidence supporting regulatory action was higher compared with those previously reported; therefore, the suggestion of Paludetto et al may not be wholly generalisable. For the majority of medicinal products identified in our study, the general trend is the longer the length of marketing prior to regulatory action, the more numerous the sources of supporting evidence (data not shown); a possible reason is additional opportunity for research to be completed using these medicinal products, thus skewing the data in favour of more numerous supporting study designs.

\section{Limitations}

It has been previously suggested by Siramshetty et al that data on product withdrawals are largely inaccessible and in that study it was found that limited data were publicly available for many of the identified products. ${ }^{39}$ Likewise in our study, five medicinal products were identified in addition to the 18 included in the analyses; it was not possible to ascertain reasons for, or evidence supporting, the withdrawal, revocation or suspension of their marketing authorisations based on publicly available data. Furthermore, most Assessment Reports produced by the EMA did not include reference lists and many stated 'all available evidence' was reviewed to support the regulatory action; this meant a PubMed search was necessary to identify evidence from the scientific literature that may have been used by the regulatory authorities in addition to those directly cited. It is unknown whether all papers identified in the scientific literature contributed to regulatory decisions; similarly additional evidence may have been considered that was not obtained during our search within just one database. The perceived robustness of evidence used to support each regulatory action is dependent on many factors with no one study design stronger than another, therefore it was not possible to determine a hierarchy of evidence supporting these regulatory actions. Moreover, the use of the INN rather than proprietary name during literature searches may have excluded some papers. Authorisation dates were not provided in regulatory documentation for most medicinal products identified; therefore, the year of initial authorisation within the EU used in this study may not have been an accurate representation of each medicinal product's length of marketing prior to regulatory action. The reasonably short study period meant the trends observed could only suggest 
possible changes in regulatory efficacy and duration of marketing prior to regulatory action; the results should therefore be interpreted cautiously. Finally, we were only able to compare our results with studies examining exclusively product withdrawals; while there is no one method for regulatory reviews of medicinal products, it has been assumed that the process and therefore sources of evidence used to support each regulatory action would be similar, regardless of the outcome. This may have affected the comparability of our results with previously completed studies.

It is important to note that not all regulatory reviews were commenced after the implementation of updated legislation in 2012. Furthermore, due to serious withdrawal symptoms associated with abruptly stopping meprobamate treatment, a gradual withdrawal of this medicinal product from market was implemented which continued throughout our study period; however, the decision date and consequently review of safety information for the suspension of meprobamate was prior to July $2012 .{ }^{40}$ It is impossible to ascertain whether the evidence used to support these regulatory actions and time to reach a regulatory decision would have been different if the review commencement or regulatory decision date was postimplementation of Directive 2010/84/EU and Regulation (EU) No. $1235 / 2010$.

Despite its limitations, this study is the first to examine the sources of evidence supporting pharmacovigilance regulatory decisions and time to reach a regulatory decision within the EU since the adoption of updated legislations which came into effect in July 2012.

\section{Future research and conclusion}

An interesting topic for future research would be to investigate the weighting of each study type contributing to regulatory decisions. Research into the impact of these regulatory actions resulting from legislative revisions on the public health burden within the EU would also be advantageous. Furthermore, it is recommended that a larger sample of medicinal products be studied over a longer duration to assess the changes to the recognition of misuse and medication error, including accidental overdose, as a reason for regulatory action. Continued monitoring of the effectiveness of these legislations is recommended to ensure an ongoing move towards strengthened evidence sources supporting regulatory actions; similarly observation of the length of future regulatory reviews will ensure the target of a shorter time to reach a regulatory decision is met. This will help to protect public health by preventing patients accessing harmful medications sooner following the detection of a safety concern.

On implementation of Directive 2010/84/EU and Regulation (EU) No. 1235/2010 throughout the EU, there was hope for more rapid decisions based on more robust supporting evidence. ${ }^{6}$ Findings of our study suggest that this has been at least somewhat successful, as recent regulatory actions were supported by multiple types of evidence, coupled with a modest decrease in the number of days to reach a decision across the time period studied. Although there is some evidence to show that alternative study designs are increasingly used to support regulatory actions, it would appear that spontaneous and published ADR reports remain the most commonly used evidence source during regulatory decision-making processes.

Acknowledgements This study has been completed as part of a commitment to the European Network of Centres for Pharmacoepidemiology and Pharmacovigilance (ENCePP) Special Interest Group on Measuring the Impact of Pharmacovigilance Activities.

Contributors All authors were involved in conception and design of the study, data interpretation, drafting and revision of the article and approval for publishing. SL was responsible for data acquisition and analyses. The guarantor for this study is SS.

Funding The DSRU is an independent charity (No. 327206) which works in association with the University of Portsmouth and is the sponsor of the study.

Competing interests None declared.

Patient consent Not required.

Ethics approval Application for ethics approval was not required due to the nature of the data.

Provenance and peer review Not commissioned; externally peer reviewed.

Data sharing statement No additional data available.

Open Access This is an Open Access article distributed in accordance with the Creative Commons Attribution Non Commercial (CC BY-NC 4.0) license, which permits others to distribute, remix, adapt, build upon this work non-commercially, and license their derivative works on different terms, provided the original work is properly cited and the use is non-commercial. See: http://creativecommons.org/ licenses/by-nc/4.0/

(c) Article author(s) (or their employer(s) unless otherwise stated in the text of the article) 2018. All rights reserved. No commercial use is permitted unless otherwise expressly granted.

\section{REFERENCES}

1. Carné X, Arnaiz JA. Methodological and political issues in clinical pharmacology research by the year 2000. Eur J Clin Pharmacol 2000;55:781-5.

2. Clarke A, Deeks JJ, Shakir SA. An assessment of the publicly disseminated evidence of safety used in decisions to withdraw medicinal products from the UK and US markets. Drug Saf 2006;29:175-81.

3. Angamo MT, Chalmers L, Curtain CM, et al. Adverse-drugreaction-related hospitalisations in developed and developing countries: a review of prevalence and contributing factors. Drug Saf 2016;39:847-57.

4. Gonzalez-Gonzalez C, Lopez-Gonzalez E, Herdeiro MT, et al. Strategies to improve adverse drug reaction reporting: a critical and systematic review. Drug Saf 2013;36:317-28.

5. Pontes H, Clément M, Rollason V. Safety signal detection: the relevance of literature review. Drug Saf 2014;37:471-9.

6. European Medicines Agency. Legal framework London: European medicines agency. $2017 \mathrm{http}: / / w w w . e m a . e u r o p a . e u / e m a / i n d e x . j s p ?$ curl=pages/special_topics/general/general_content_000491.jsp\& $\mathrm{mid}=$ WC0b01ac058058f32d

7. Strengthening pharmacovigilance to reduce adverse effects of medicines. Brussels, 2008.

8. Borg JJ, Aislaitner G, Pirozynski M, et al. Strengthening and rationalizing pharmacovigilance in the EU: where is Europe heading to? A review of the new EU legislation on pharmacovigilance. Drug Saf 2011;34:187-97.

9. Aronson JK. Post-marketing drug withdrawals: pharmacovigilance success, regulatory problems. Therapie 2017;72:555-61. 
10. Alves $C$, Macedo AF, Marques FB. Sources of information used by regulatory agencies on the generation of drug safety alerts. Eur $\mathrm{J}$ Clin Pharmacol 2013;69:2083-94.

11. McNaughton R, Huet G, Shakir S. An investigation into drug products withdrawn from the EU market between 2002 and 2011 for safety reasons and the evidence used to support the decisionmaking. BMJ Open 2014;4:e004221.

12. Olivier $\mathrm{P}$, Montastruc $\mathrm{JL}$. The nature of the scientific evidence leading to drug withdrawals for pharmacovigilance reasons in France. Pharmacoepidemiol Drug Saf 2006;15:808-12.

13. Arnaiz JA, Carné X, Riba N, et al. The use of evidence in pharmacovigilance. Case reports as the reference source for drug withdrawals. Eur J Clin Pharmacol 2001;57:89-91.

14. Onakpoya IJ, Heneghan CJ, Aronson JK. Post-marketing withdrawal of 462 medicinal products because of adverse drug reactions: a systematic review of the world literature. BMC Med 2016;14:10.

15. Paludetto MN, Olivier-Abbal P, Montastruc JL. Is spontaneous reporting always the most important information supporting drug withdrawals for pharmacovigilance reasons in France? Pharmacoepidemiol Drug Saf 2012;21:1289-94.

16. Mendes D, Alves C, Batel Marques F. Testing the usefulness of the number needed to treat to be harmed (NNTH) in benefitrisk evaluations: case study with medicines withdrawn from the European market due to safety reasons. Expert Opin Drug Saf 2016;15:1301-12.

17. Sanson-Fisher RW, Bonevski B, Green LW, et al. Limitations of the randomized controlled trial in evaluating population-based health interventions. Am J Prev Med 2007;33:155-61.

18. Inácio $P$, Cavaco A, Airaksinen M. The value of patient reporting to the pharmacovigilance system: a systematic review. $\mathrm{Br} J$ Clin Pharmacol 2017;83:227-46.

19. Golder S, Loke YK, Wright K, et al. Reporting of Adverse Events in Published and Unpublished Studies of Health Care Interventions: A Systematic Review. PLoS Med 2016;13:e1002127.

20. Pagotto C, Varallo F, Mastroianni P. Impact of educational interventions on adverse drug events reporting. Int J Technol Assess Health Care 2013;29:410-7.

21. Ribeiro-Vaz I, Silva AM, Costa Santos C, et al. How to promote adverse drug reaction reports using information systems - a systematic review and meta-analysis. BMC Med Inform Decis Mak 2016;16:27.

22. McGettigan P, Golden J, Conroy RM, et al. Reporting of adverse drug reactions by hospital doctors and the response to intervention. $\mathrm{Br} J$ Clin Pharmacol 1997:44:98-100.

23. Smith CC, Bennett PM, Pearce HM, et al. Adverse drug reactions in a hospital general medical unit meriting notification to the committee on safety of medicines. Br J Clin Pharmacol 1996;42:423-9.

24. Biagi C, Montanaro N, Buccellato E, et al. Underreporting in pharmacovigilance: an intervention for Italian GPs (Emilia-Romagna region). Eur J Clin Pharmacol 2013;69:237-44.

25. Califf RM, Robb MA, Bindman AB, et al. Transforming evidence generation to support health and health care decisions. N Engl J Med 2016;375:2395-400.

26. Agency EM. Questions and answers: urgent union procedures. 2015 http://www.ema.europa.eu/ema/index.jsp?curl=pages/regulation/
q_and_a/q_and_a_detail_000131.jsp\&mid=WC0b01ac058061f6fb\# section4

27. Agency EM. Questions and answers: article 31 pharmacovigilance referrals. $2015 \mathrm{http}: / / w w w . e m a . e u r o p a . e u / e m a / i n d e x . j s p ? c u r l=$ pages/regulation/q_and_a/q_and_a_detail_000144.jsp\&mid= WC0b01ac0580789970

28. Agency EM. Q\&A: article 20 pharmacovigilance procedures 2017. $2017 \mathrm{http} / / / w w w . e m a . e u r o p a . e u / e m a / i n d e x . j s p ? c u r l=$ pages/regulation/q_and_a/q_and_a_detail_000018.jsp\&mid= WC0b01ac0580024e97\#

29. European Medicines Agency. Guideline on good pharmacovigilance practices (GVP) annex I - definitions (Rev 3)). London: European Medicines Agency, 2014.

30. European Medicines Agency. Periodic safety update reports. 2017 http://www.ema.europa.eu/ema/index.jsp?curl=pages/regulation/ document_listing/document_listing_000361.jsp

31. European Medicines Agency. Codeine-containing medicinal products for the treatment of cough or cold in paediatric patients London: European medicines agency. $2015 \mathrm{http}: / / w w w . e m a . e u r o p a . e u /$ ema/index.jsp?curl=pages/medicines/human/referrals/Codeine containing_medicinal_products_for_the_treatment_of_cough_and cold_in_paediatric_patients/human_referral_prac_000039.jsp\&mid= WC0b01ac05805c516f

32. Avorn J. In defense of pharmacoepidemiology--embracing the yin and yang of drug research. N Engl J Med 2007;357:2219-21.

33. Fung M, Thornton A, Mybeck K, et al. Evaluation of the characteristics of safety withdrawal of prescription drugs from worldwide pharmaceutical markets-1960 to 1999. Drug Inf $J$ 2001;35:293-317.

34. Lasser KE, Allen PD, Woolhandler SJ, et al. Timing of new black box warnings and withdrawals for prescription medications. JAMA 2002;287:2215-20.

35. Borg JJ, Tanti A, Kouvelas D, et al. European union pharmacovigilance capabilities: potential for the new legislation. Ther Adv Drug Saf 2015;6:120-40.

36. Jefferys DB, Leakey D, Lewis JA, et al. New active substances authorized in the United Kingdom between 1972 and 1994. Br J Clin Pharmacol 1998;45:151-6.

37. Agency EM. Periodic safety update reports: questions and answers. $2017 \mathrm{http}: / /$ www.ema.europa.eu/ema/index.jsp?curl=pages/ regulation/q_and_a/q_and_a_detail_000041.jsp

38. Agency EM. Adaptive pathways. 2017 http://www.ema.europa.eu/ ema/index.jsp?curl=pages/regulation/general/general_content_ 000601.jsp

39. Siramshetty VB, Nickel J, Omieczynski C, et al. WITHDRAWN--a resource for withdrawn and discontinued drugs. Nucleic Acids Res 2016;44:D1080-D1086.

40. European Medicines Agency. Assessment report for meprobamatecontaining medicinal products for oral use. London: European Medicines Agency, 2012.

41. Song JW, Chung KC. Observational studies: cohort and case-contro studies. Plast Reconstr Surg 2010;126:2234-42.

42. Haidich AB. Meta-analysis in medical research. Hippokratia 2010;14(Suppl 1):29-37.

43. Levin KA. Study design VI - ecological studies. Evid Based Dent 2006;7:108. 